\title{
MOTOR ABILITY PROFILE OF 9-12 YEARS OLD TAEKWONDO ATHLETES
}

\author{
Silvia Ilieva-Sinigerova \\ National Sports Academy "Vassil Levski", Sofia, Bulgaria
}

\begin{abstract}
The purpose of the present study was to compare motor abilities in young male and female Bulgarian taekwondo athletes. Knowing sensible periods and age and gender characteristics could be used as best predictor to determine the athletic ability. Methodology: The study included 137 taekwondo ITF athletes, profiled as male $(n=99,10.58 \pm 1.13$ years, $148.06 \pm 11.06 \mathrm{~cm}, 42.77 \pm 11.61 \mathrm{~kg})$ and female $(n=38,10.24 \pm 0.97$ years, $145.16 \pm 9.87 \mathrm{~cm}, 40.92 \pm 10.88 \mathrm{~kg})$ from 9 local taekwondo clubs in Bulgaria. Fundamental parameters of anaerobic capacity were assessed. Data were analyzed with T-test for independent samples. Results: The male showed significant $(p<0.05)$ higher value in push-ups $(26.16 \pm 7.33$ vs $23.05 \pm 8.16)$ than female. The female showed significant $(p<0.05)$ higher value in slope forward by Euro fit (2.62 \pm 8.53 vs $6.35 \pm 7.45)$ than male. Two groups had demonstrated almost equal level of motor ability. Discussion: According to various authors (Toskovic et al., 2004; Markovic et al., 2005) there are limited studies that have examined push-ups and sit-ups of international taekwondo athletes. However present research has been able to support the fact that motor abilities play an important role in improving combat performance. The main five components of motor ability (flexibility, endurance, strength, power and cardiorespiratory fitness) (Ruiz et al., 2006) were assessed in junior taekwondo athletes. Conclusions: The results showed that the performance of females in flexibility is better than males. Males demonstrated higher value in strength than females. At the age 9-12 taekwondo athletes (males and females) had demonstrated almost equal level of motor ability.
\end{abstract}

Key words: taekwondo, motor ability, young athletes

\section{INTRODUCTION}

Taekwondo can be described as a high-intensity martial art and modern Olympic sport, in which the main purpose is to defeat the opponent using quick and precise kicks (Cular et al., 2013). Taekwondo requires explosive strength, flexibility and balance. Competitors must be able to move with high velocity, speed and power. Explosive strength, balance, flexibility and agility contribute to faster and better executed taekwondo skills. Studies have found that movement speed and coordination are the most fundamental components of successful taekwon-do performance (Boraczynski et al., 2017). The most important success factors in sports include body build, conditioning, technical and tactical skills, mental abilities and the experience of a competitor (Toskovic et al., 2013). With respect to youth sport performance, the use of techniques to assist with talent identification and performance within the junior from 10-12 years for boy's phase of growth as competitive sport is not a regular occurrence in children. It was important to develop of motor skills and skill for juniors in ages (10-12) years in order to installed and development vital to the efficiency of a comprehensive fitness elements of public (Khaled, 2013). Specific motor abilities of age phase (11-12 years) needs to develop and specify of training programs (Bakr, 2016).

The aim of the present study was to compare motor abilities in young male and female Bulgarian taekwondo athletes.

\section{METHODOLOGY}

The study was conducted in the period from 25/03/2019 to 19.05 .2019 and included 137 taekwondo ITF athletes, profiled as male $(n=99,10.58$ \pm 1.13 years, $148.06 \pm 11.06 \mathrm{~cm}, 42.77 \pm 11.61 \mathrm{~kg}$ ) and female $(\mathrm{n}=38,10.24 \pm 0.97$ years, $145.16 \pm 9.87$ $\mathrm{cm}, 40.92 \pm 10.88 \mathrm{~kg}$ ) from 9 local taekwondo clubs in Bulgaria. All the participants were freely volunteered to participate in this study. Data were analyzed with T-test for independent samples.

\section{Procedure}

The following tests were administered: measurements such as flexibility (split and slope forward by Euro fit), explosive leg strength (long jump and vertical jump), endurance (300/600 meters run), aerobic power (shuttle run $8 \times 10$ meters), leaps over the gym bench laterally, abdominal and upper limbs strength and endurance (throwing a medical ball, push-ups and sit - ups). 
Statistical analysis Data were analyzed using mean and standard deviations. The t-test was computed to determine if differences exist between male and female athletes. Significance was set at $\mathrm{p}<0.05$ and $\mathrm{p}<0.001$. Z-score radar plots were applied for comparison between males and females. All statistical analyses were performed using SPSS version 25.

\section{RESULTS}

In Table 1 are presented the results of the descriptive statistics of the performance variables in male and female athletes. Males tend to have higher results of leaps over the gym bench laterally and push-ups. Females tend to have higher results in slope forward by Euro fit and splits. No significant difference was noted in the following tests: throwing a medical ball, long jump, vertical jump, shuttle run $8 \times 10$ meters, sit-ups and 600 meters run. Statistically, significant higher difference $(\mathrm{p}<0.001)$ in split (left side, right side and side twin) and slope forward by Euro fit $(\mathrm{p}<0.05)$ was found in female athletes when compared to males. Significant higher difference $(\mathrm{p}<0.05)$ in leaps over the gym bench laterally and push-ups was found in male athletes compared to females. Two groups had demonstrated almost equal level of motor ability.

Table 1. Physical characteristics between 9-12 years old male vs 9-12 years old female (mean $\pm S D$ ).

\begin{tabular}{|l|c|c|c|c|}
\hline \multicolumn{1}{|c|}{ Parameters } & Male (n=99) & Female (n=38) & $\Delta$ & $\Delta \%$ \\
\hline Age (years) & $10.58 \pm 1.13$ & $10.24 \pm 0.97$ & -0.34 & 3.21 \\
\hline Height (kg) & $42.78 \pm 11.60$ & $40.92 \pm 10.87$ & -1.86 & 4.34 \\
\hline Throwing a medical ball (cm) & $148.05 \pm 11.06$ & $145.15 \pm 9.86$ & -2.89 & 1.95 \\
\hline Long jump (cm) & $318.97 \pm 93.79$ & $291.53 \pm 75.91$ & -27.44 & 8.60 \\
\hline Vertical jump (cm) & $160.94 \pm 26.05$ & $160.65 \pm 27.02$ & -0.29 & 0.18 \\
\hline $\begin{array}{l}\text { Leaps over the gym bench } \\
\text { laterally (number) }\end{array}$ & $21.01 \pm 7.85$ & $22.85 \pm 8.42$ & 1.84 & 8.75 \\
\hline Shuttle run 8x10 meters (sec) & $28.64 \pm 5.63$ & $29.90 \pm 6.84$ & 1.26 & 4.39 \\
\hline Push-ups (number) & $* 26.16 \pm 7.33$ & $23.05 \pm 8.16$ & -3.11 & 11.88 \\
\hline Sit-ups (number) & $22.41 \pm 7.74$ & $23.66 \pm 8.39$ & 1.25 & 5.57 \\
\hline 600 meters run (sec) & $133.36 \pm 11.77$ & $130.30 \pm 15.19$ & -3.06 & 2.29 \\
\hline $\begin{array}{l}\text { Slope forward by Euro fit } \\
\text { (cm) }\end{array}$ & $2.79 \pm 8.47$ & $* 6.35 \pm 7.45$ & 3.56 & 127.59 \\
\hline Split - left side (cm) & $-14.97 \pm 10.08$ & $* *-8.47 \pm 8.98$ & 6.5 & 43.42 \\
\hline Split - right side (cm) & $-16.02 \pm 10.56$ & $* *-7.25 \pm 9.52$ & 8.77 & 54.74 \\
\hline Side twine (cm) & $-15.55 \pm 9.56$ & $* *-7.71 \pm 8.29$ & 7.84 & 50.41 \\
\hline
\end{tabular}

${ }^{* *} p<0.001,{ }^{*} p<0.05, \Delta$ : change, \% percentage, cm: centimeters, kg: kilograms

In Figure 1 to 4 are presented individual results of was made according to the age of the athletes and some athletes. They were chosen at random and the representatives of both genders were selected. Six of initials of their names were given. The comparison the tests were selected. 
VK and KM (A)

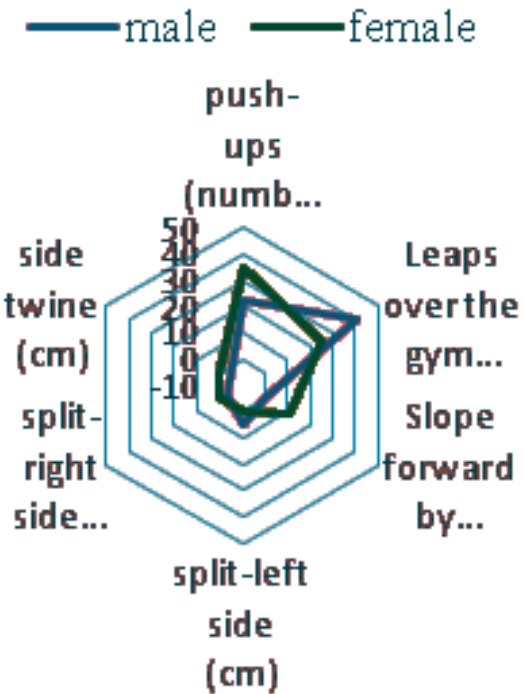

EL and SI (B)

-male female

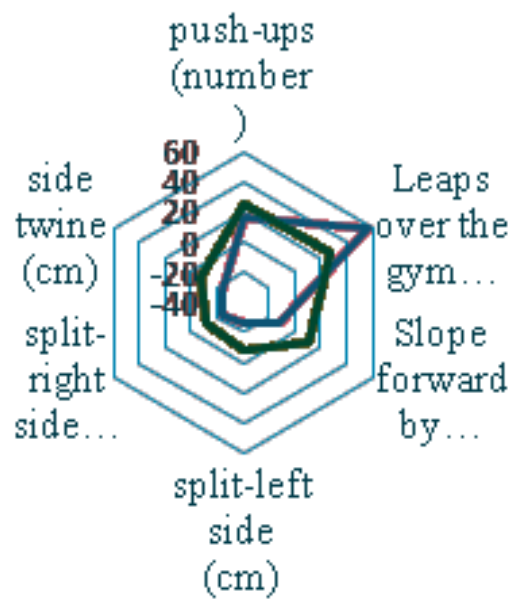

Figure 1. Compare between motor ability of 9-year-old male and female athletes (A) and between motor ability of 10-year-old male and female athletes (B)

Results in Figure 1 (A) displayed a higher level of points. On the other hand, female athlete SI showed leaps over the gym bench for male. Female athlete higher level of flexibility and push-ups. High flexiKM displayed higher level of flexibility and push- bility helps the athlete to reach the targeted area ups. Her kicking execution will be strong when during a fight. Strikes in the head area earn more attacking an opponent. High flexibility helps the points.

athlete to reach the targeted area during a fight. Results in Figure 2 (A) displayed almost equal vaComparison between 10 years old athletes displa- lues of push-ups, leaps over the gym bench and slope yed a higher level of leaps over the gym bench for forward by Euro fit by two athletes. Both athletes EL male (figure 1 (B)). The athlete showed very low presented good level of upper limbs strength and enlevel of flexibility, which will make it difficult to durance. At the same time, however, GB performed reach the target during sparring and earning less higher values on the other flexibility tests.

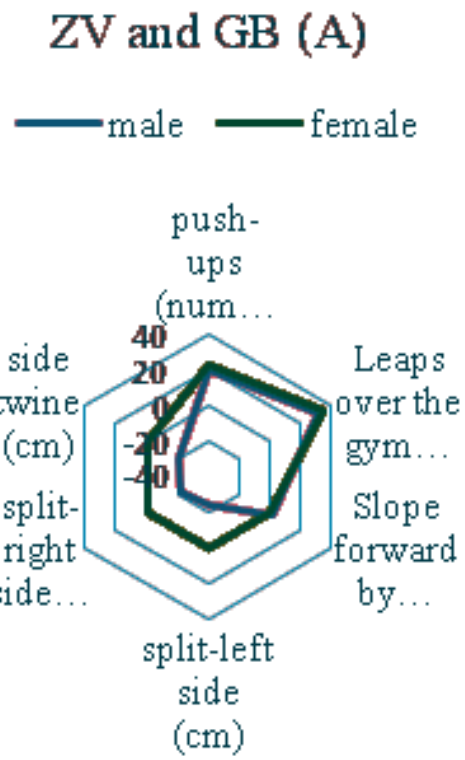

\section{MS and AM (B)}
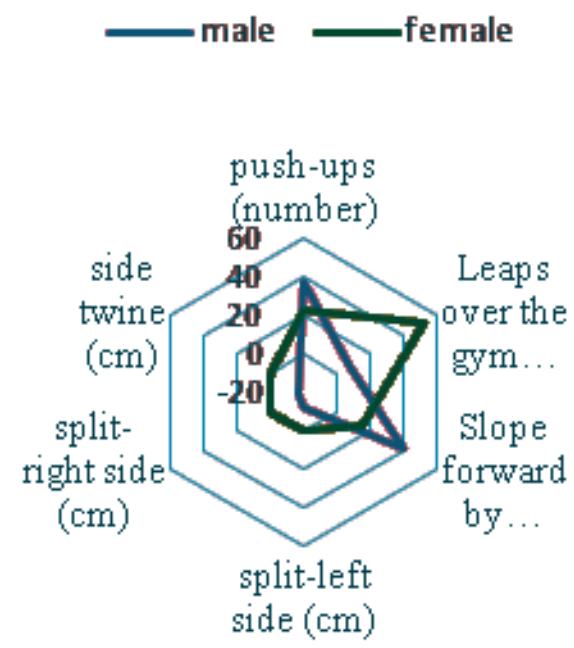

Figure 2. Compare between motor ability of 11-year-old male and female athletes (A) and between motor ability of 12-year-old male and female athletes (B) 
Comparison between 12 years old athletes (Figure 2 (B)) displayed higher level of push-ups and slope forward by Euro fit by MS male athlete. On the other hand, his flexibility and endurance of the lower limb were very low. He, therefore, needs to avoid effective kicks from an opponent by always counter attacking, so that he can endure longer during fights since his muscular endurance is poor. Female athlete AM showed higher level of flexibility and endurance of the lower limbs, but low level of upper limbs strength and endurance.

\section{CONCLUSIONS}

The data obtained that the performance of females in flexibility is better than males. Males demonstrated higher value in strength than females. At the age 9-12 taekwondo athletes (males and females) had demonstrated almost equal level of motor ability. Considering the age and gender characteristics and the paucity of studies of motor abilities in 9-12year old, it is necessary to carry out systematic and targeted studies in order to be able to make clearer conclusions.

\section{DISCUSSION}

According to various authors (Toskovic et al., 2004; Markovic et al., 2005) there are limited studies that have examined push-ups and sit-ups of international taekwondo athletes. However present research has been able to support the fact that motor abilities play an important role in improving combat performance. The main five components of motor ability (flexibility, endurance, strength, power and cardiorespiratory fitness) (Ruiz et al., 2006) were assessed in junior taekwon athletes. Markovic et al. (2005) observed no significant difference between successful and unsuccessful female taekwondo athletes in flexibility. On the other hand, training adaptation and the technical demands of sport produces higher flexibility which explains the reason why senior athletes display higher flexibility scores than the juniors (Bridge et al., 2014). Whereas, the status of prioritize the characteristics as the highlighted factors in trainings and talent identification in this sport still remained unknown (Arazi \& Izadi, 2006). Additionally, there is lack of information regarding age and development in taekwon-do making it challenging to determine the impact of differences in physical profile between junior male and female athletes (Mathunjwa et al., 2017).

\section{REFERENCES}

Arazi, H., Hosseinzadeh, Z. \& Izadi, M. (2006). Relationship between anthropometric, physiological and physical characteristics with success of female taekwondo athletes, Turkish Journal of Sport and Exercise. 18 (2), pp.69-75.

Bakr, M. (2016). Growth rates and specific motor abilities as a function to predict the selection of talents taekwondo sport (Egyptian national project), Turk J Kin, 2 (1), pp.1-5. Ball, N., Nolan, E. \& Wheelere K. (2011). Anthropometrical, physiological, and tracked power profiles of elite taekwondo athletes 9 weeks before the Olympic competition phase. Journal of Strength Conditioning and Resistance. 25, pp. 2752-2763.

Boraczynski, M. et al. (2017). Relationship between anthropometric features, body composition and anaerobic alactic power in elite post-pubertal and mature male taekwondo athletes. Human movement, 18 (4), pp. 30-40.

Bridge C. A. et al. (2014). Physical and Physiological Profiles of Taekwondo Athletes. Sports Medicine, 44 (6), pp. 713-733.

Cular, D. et al. (2013). Predictors of Fitness Status on Success in Taekwondo, Anthropological, 4, pp. 1267-1274.

Khaled, E. (2013). Anthropometric measurements, somatotype and physical abilities as a function to predict the selection of talents junior weightlifters. Science, Movement and Health, 13 (2), pp. 166-172.

Markovic, G., Misigo-Durakovic, M. and Trninic S. (2005). Fitness profile of elite Croatian female taekwondo athletes. Collegium Anthropologicum, 29 (1), pp. 93-99. Mathunjwa, M. et al. (2017). Motor ability profile of junior and senior male South African taekwondo athletes, Journal of Applied Sports Science, 2, pp. 5-11.

Pion, J. et al. (2014). The value of non-sport-specific characteristics for talent orientation in young male judo, karate and taekwondo athletes, Archives of Budo, Science of martial arts, 10, pp. 147-154.

Ruiz, J. R., et al. (2006). Health-related fitness assessment in childhood and adolescence: A European approach based on the Aven, Eyha and Helena studies, Journal of Public Health, 14, pp. 269-277.

Sadowski, J., et al. (2012). Success factors in male WTF taekwondo juniors, Journal of combat sports and martial arts, 3, pp. 47-51.

Toskovic, N. N., Blessing, D. \& Williford. H. N. (2004). Physiologic profile of recreational male and female novice and experienced Tae Kwon Do practitioners. Journal of Sports Medicine and Physical Fitness, 44 (2), pp. 164-172.

Corresponding author:

Silvia Ilieva - Sinigerova

National Sports Academy "Vassil Levski"

“Theory of Sport” dep., Studentski grad, Sofia 1700, Bulgaria

E-mail: nsastatics@gmail.com 